\title{
Optimization of Heat Treatment in AZ64 Magnesium Alloy
}

\author{
Songmao Liang*1, Yuequn Ma, Rongshi Chen*2 and Enhou Han \\ Environmental Corrosion Center, Institute of Metal Research, Chinese Academy of Sciences, \\ 72 Wenhua Road, Shenyang 110016, P.R. China
}

The heat treatment parameters of AZ64 magnesium alloy have been optimized using thermal analysis, scanning electron microscopy and $\mathrm{X}$-ray diffraction techniques. The thermal analysis result revealed that two precipitation reactions took place during the solidification of AZ64 alloy. Therefore, a two-step solution heat treatment method, instead of traditional solution treatment whose temperature was about $10^{\circ} \mathrm{C}$ below the solidus temperature, was developed corresponding to the dissolution of two precipitate phases. With comparison to the traditional heat treatment, the two-step treatment method could generate a complete solution effect. During the following aging process, precipitates almost uniformly dispersed throughout the matrix, thus improve the tensile strength of alloy. [doi:10.2320/matertrans.MC200756]

(Received October 10, 2007; Accepted December 21, 2007; Published April 25, 2008)

Keywords: AZ64 magnesium alloy, thermal analysis, two-step solution treatment, mechanical properties

\section{Introduction}

Currently, the most widely used magnesium alloys on automobile components are those based essentially on the $\mathrm{Mg}-\mathrm{Al}$ system, such as AZ91, AM60 and AM50. ${ }^{1)}$ However, the poor ductility of AZ91 and low yield strength of AM60/ 50 have restricted their applications, such as on the wheels of lightweight vehicles, where high strength and high ductility are required simultaneously. ${ }^{2}$ ) In our previous work, we discovered that AZ64 possessed high strength and ductility in comparison with commercial AZ91 and AM60 alloys. ${ }^{3)}$ Heat treatment is a relative cheap and effective way to improve the mechanical properties of cast components. In this study, heat treatment conditions of the AZ64 alloys were optimized, and the effects of the heat treatment condition on mechanical properties was also investigated.

\section{Experimental Procedures}

The AZ64 alloy was prepared in a mild steel crucible using commercial high purity raw materials. Smelting process was carried out in an electrical resistance furnace with $15 \mathrm{~kg}$ capacity. The content of $\mathrm{MgCO}_{3}$ in magnesite particles was more than 98 mass $\%$ and the addition of magnesite particles to the melt accounts for 1.5 mass $\%$ of the total weight of raw materials. Chemical analysis results of the alloy composition is $\mathrm{Mg}-6.0 \mathrm{Al}-4.1 \mathrm{Zn}-0.37 \mathrm{Mn}(\operatorname{mass} \%)$. Observations of the microstructure were conducted on a Philips XL30 ESEMFEG/EDAX scanning electron microscope (SEM). The compositions of the secondary phases were analyzed by Energy Dispersive Spectroscopy (EDAX), and the reported values are the average of 10 measurements for each phase. Xray Diffraction (XRD) experiments were carried out on a Rigaku D/max 2400 X-ray diffractometer with monochromated $\mathrm{CuK} \alpha$ radiation. The solidification pathway of the alloy was investigated by a computer-based thermal analysis

\footnotetext{
${ }^{* 1}$ Graduate Student, Graduate School of the Chinese Academy of Sciences. Present address: Institute of Metal Research, Chinese Academy of Sciences, 72 Wenhua Road, Shenyang, 110016, P.R. China

${ }^{* 2}$ Corresponding author, E-mail: rschen@imr.ac.cn
}

system, which was described detailedly in our previous study. ${ }^{4)}$ The data collected by the center thermocouple was used to analyze the phase transition characteristics.

Samples for solid solution treatment were holding at designed temperature in an electrical furnace for required time and the then quenched in cold water. Then they were subsequently aged at $180^{\circ} \mathrm{C}$ for $20 \mathrm{~h}$. Tensile samples were prepared with a gauge dimension of $36 \times 10 \times 3 \mathrm{~mm}$. Tensile tests were carried out for both the as-cast and heattreated samples using a fully computerized universal testing machine with the head displacement rate $2 \mathrm{~mm} / \mathrm{min}$.

\section{Results and Discussion}

\subsection{As-cast microstructure}

The microstructure of as-cast AZ64 alloy is shown in Fig. 1(a). In addition to the $\alpha-\mathrm{Mg}$ matrix, two distinct secondary phases can be observed along the grain boundaries. EDAX analysis show that the gray phase is $\gamma$ $\operatorname{Mg}_{17}(\mathrm{Al}, \mathrm{Zn})_{12}$ phase with an average composition of $\mathrm{Mg}_{60} \mathrm{Al}_{31} \mathrm{Zn}_{9}($ at\% $)$, and the white phase is $\phi$ phase $\left(\mathrm{Mg}_{21}(\mathrm{Al}, \mathrm{Zn})_{17}\right)$ with an average composition of $\mathrm{Mg}_{55} \mathrm{Al}_{14} \mathrm{Zn}_{21}($ at $\%)$. In addition to the grain boundary phases, some $\gamma$-phase precipitates can also be observed near the grain boundary and develop into grain interior. The XRD pattern of the alloy as shown in Fig. 1(b) confirmed that AZ64 alloy is composed of three phases, which are $\alpha-\mathrm{Mg}, \gamma$ $\operatorname{Mg}_{17}(\mathrm{Al}, \mathrm{Zn})_{12}$ phase and $\phi$-phase $\left(\mathrm{Mg}_{21}(\mathrm{Al}, \mathrm{Zn})_{17}\right)$.

\subsection{Thermal analysis and solidification pathway}

Figure 2 shows the cooling curve and first derivative curve of AZ64. The first peak in the first derivative curve represents the formation of primary $\alpha-\mathrm{Mg}$ phase. In addition, one can observe other two evident peaks at $382^{\circ} \mathrm{C}$ and $354^{\circ} \mathrm{C}$ which represent the intermetallic compounds formation reactions occur during the solidification after $\alpha-\mathrm{Mg}$ formation. Figure 3 reproduces the $\mathrm{Mg}-\mathrm{Al}-\mathrm{Zn}$ (Mg-rich corner) ternary phase diagram developed by H. Liang. ${ }^{5)}$ During solidification, the solute elements would be rejected into the liquid. As a result, the liquid composition might follow the dash line coming to point $b$ encountered with eutectic valley, then 


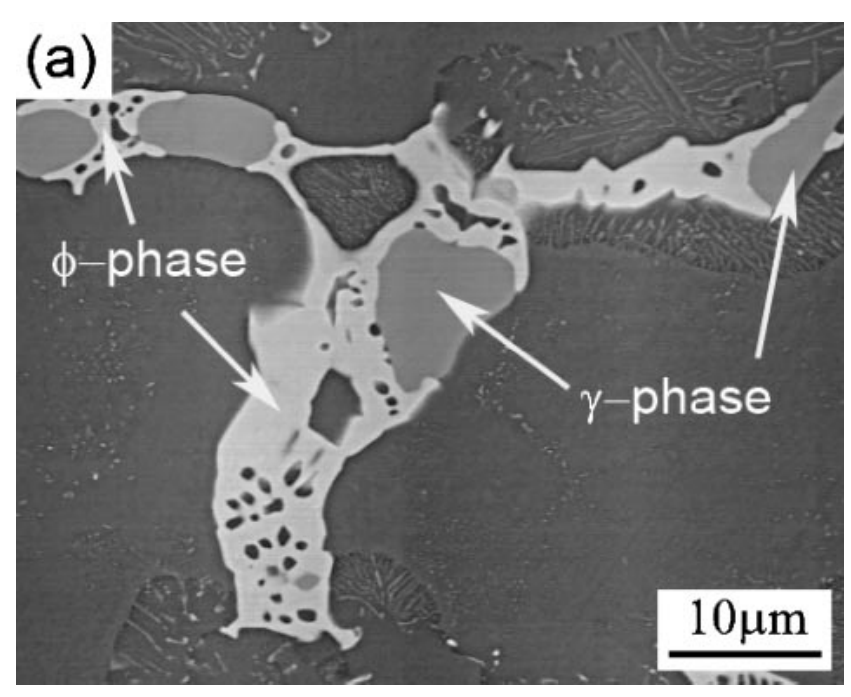

(b)

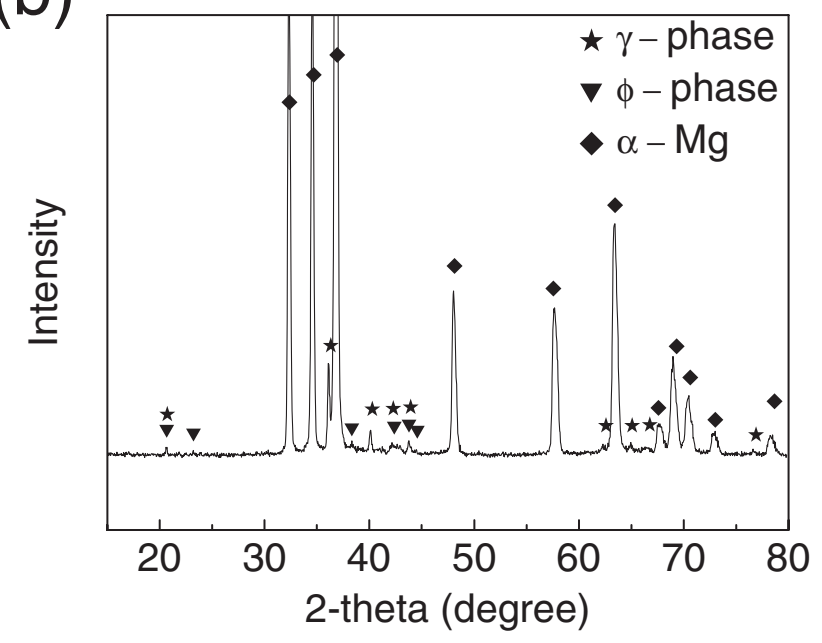

Fig. 1 (a) As-cast microstructure and (b) XRD pattern of AZ64 alloy.

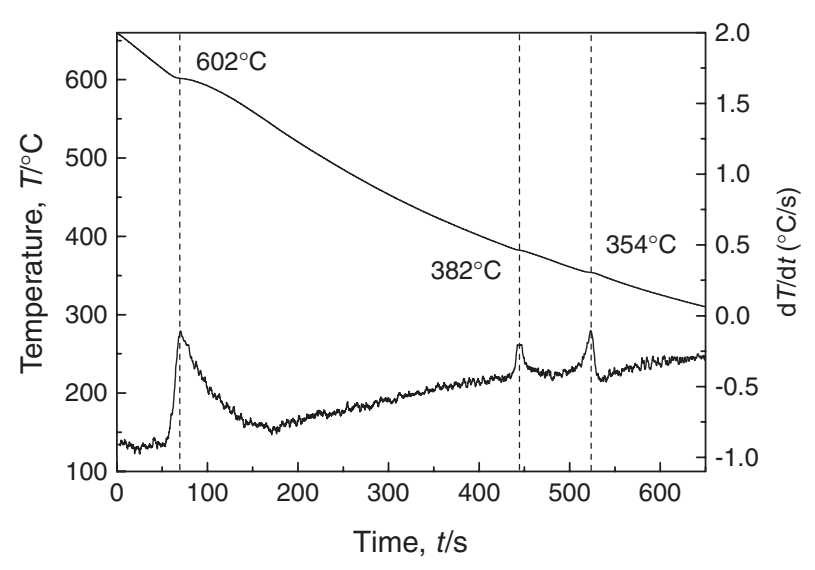

Fig. 2 The cooling curve and first derivative curve of AZ64 alloy.

binary eutectic $\mathrm{L} \rightarrow \alpha-\mathrm{Mg}+\gamma$-phase occurred. With the further decrease of temperature, the remained liquid composition would develop along the eutectic valley and reach the ternary eutectic $\mathrm{L} \rightarrow \alpha$-Mg $+\gamma$-phase $+\phi$-phase, which terminated the solidification. So it can be concluded that in the first derivative curve the peak at $382^{\circ} \mathrm{C}$ represents the binary eutectic reactions and the peak at $354^{\circ} \mathrm{C}$ is generated

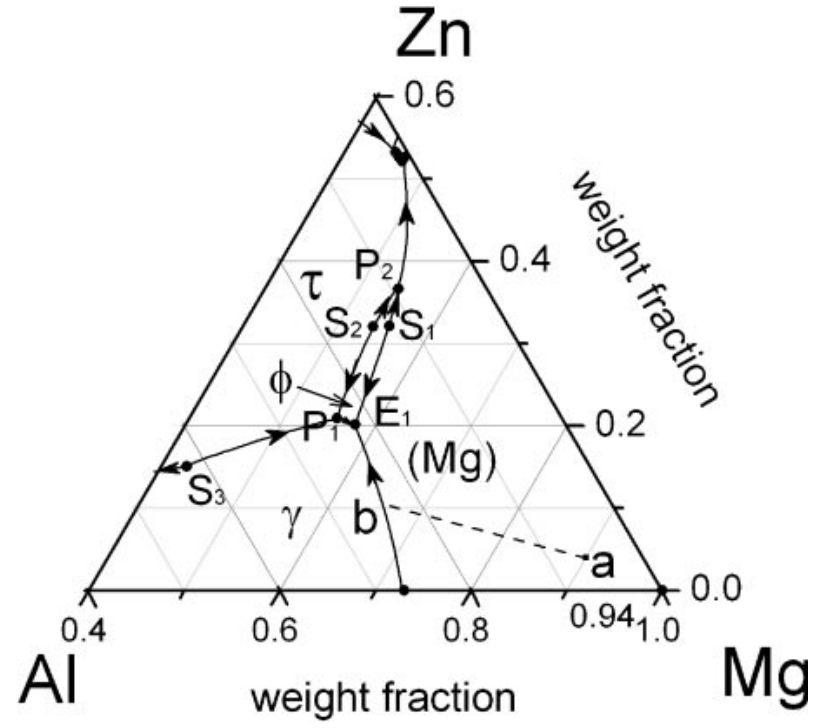

Fig. 3 The liquidus projection of $\mathrm{Mg}-\mathrm{Al}-\mathrm{Zn}$ ternary system at $\mathrm{Mg}$-rich corner.
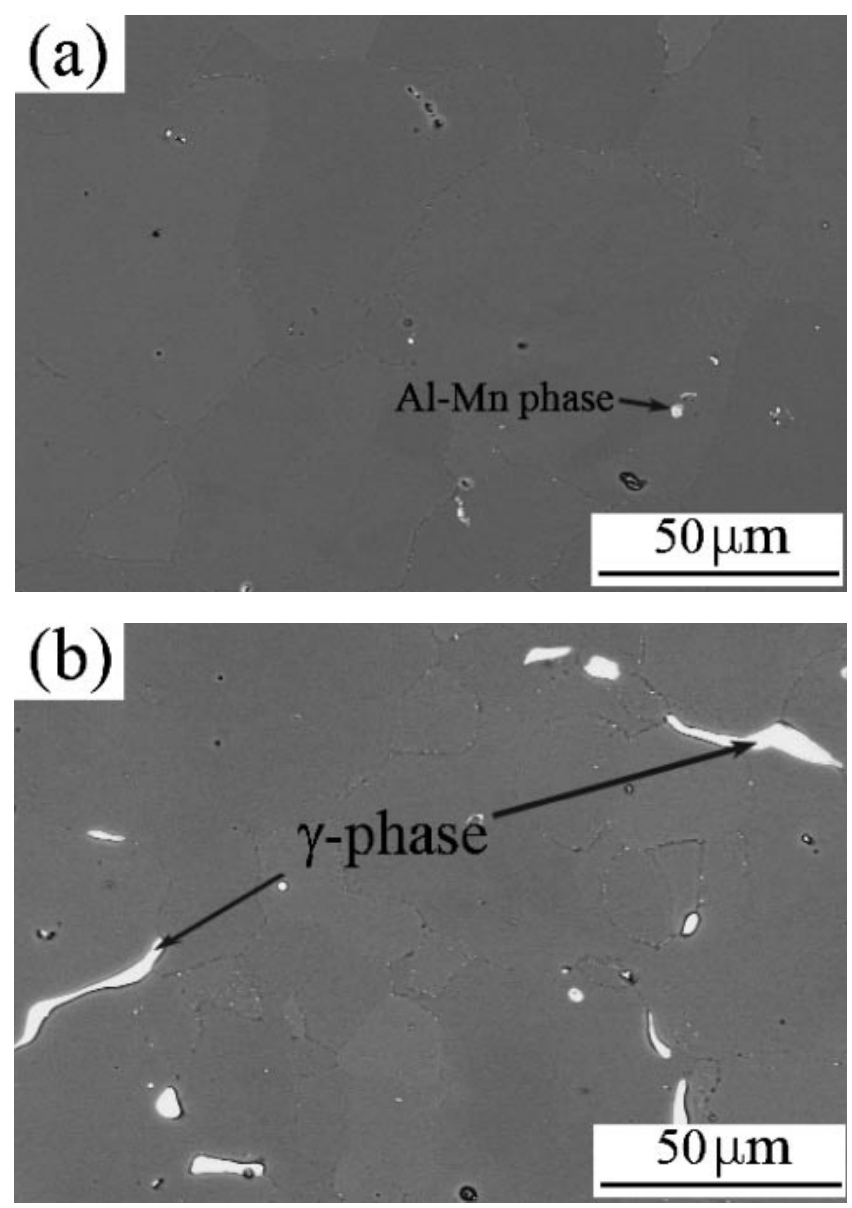

Fig. 4 Microstructure of AZ64 after (a) new T4 treatment (T4-I) and (b) traditional $\mathrm{T} 4$ treatment $(\mathrm{T} 4)$.

by ternary eutectic reactions. It should be mentioned that this solidification is under non-equilibrium condition, so their temperatures are derivate from equilibrium values. The thermal analysis results are in accordance with the microstructure observation and XRD analysis shown in Fig. 1. 

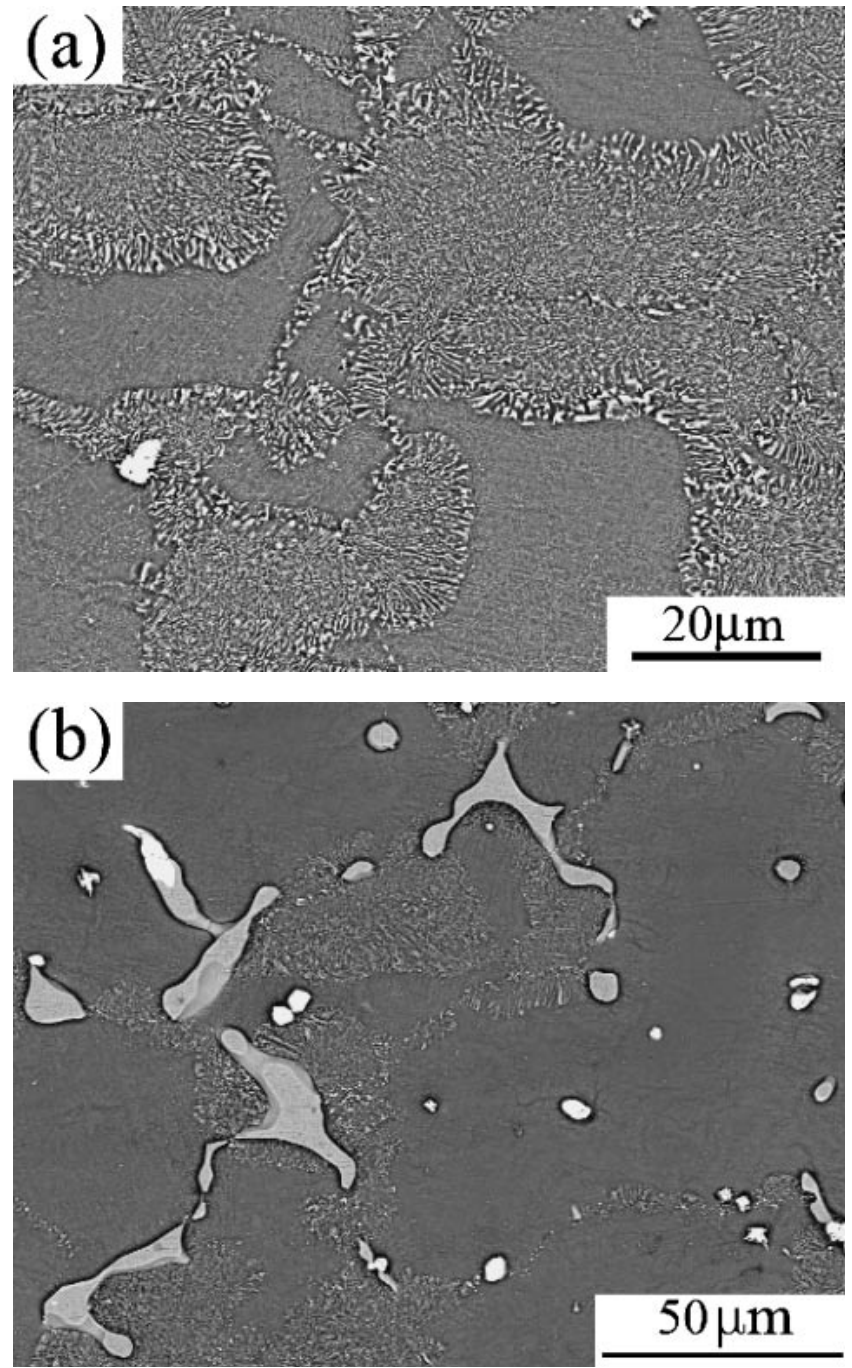

Fig. 5 Microstructure of AZ64 after (a) T6-I and (b) T6 heat treatment.

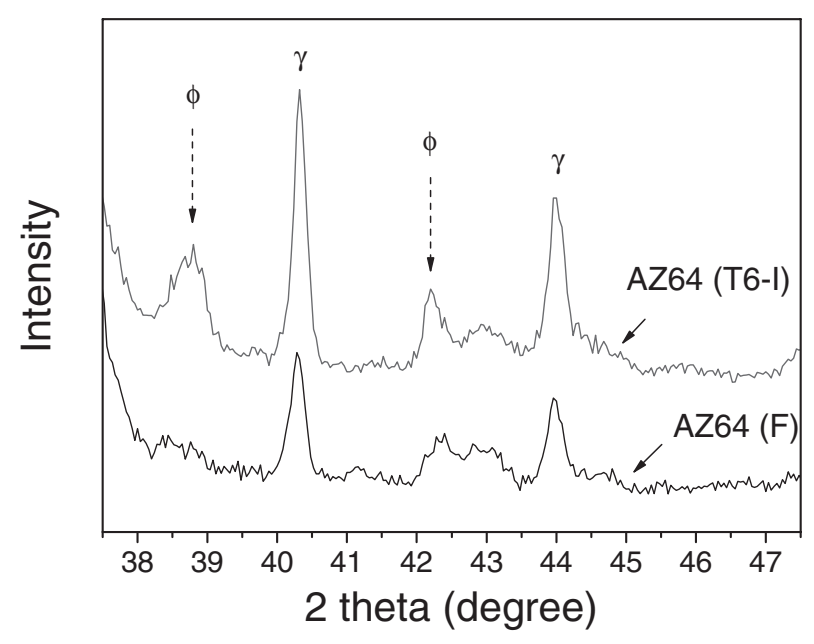

Fig. 6 XRD pattern of the sample after T6-I treatment compared with ascast state.

\subsection{Heat treatment}

Based on the thermal analysis results, we develop a twostep solution heat treatment procedure. First, the heat treatment temperature is set as $345^{\circ} \mathrm{C}$, after holding $10 \mathrm{~h}$,

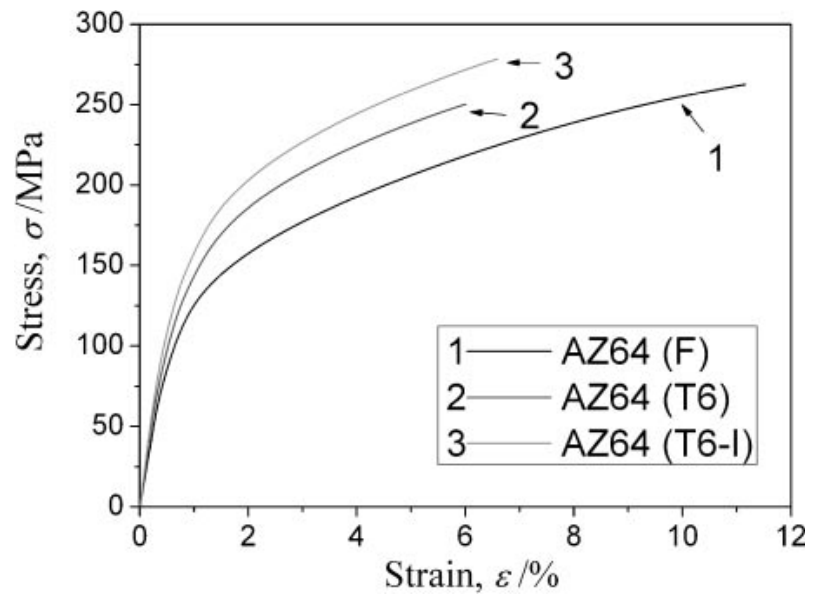

Fig. 7 The effects of heat treatment on the tensile mechanical properties of AZ64 alloy.

most of the $\gamma$-phase and $\phi$-phase formed through ternary eutectic are dissolved into the Mg matrix, and only a small of amount of $\gamma$ phase remains undissolved. Then increasing the treatment temperature to $370^{\circ} \mathrm{C}$, after 2 hours' treatment, all $\mathrm{Mg}-\mathrm{Al}-\mathrm{Zn}$ intermetallic compounds can be dissolved into $\mathrm{Mg}$ matrix except very small fraction of Al-Mn phase. The microstructure of alloy after heat treatment is shown in Fig. 4(a). On the other hand, for traditional T4 heat treatment, setting treatment temperature as $345^{\circ} \mathrm{C}$, which is about $10^{\circ} \mathrm{C}$ lower than the solidus temperature of the alloy, even after $16 \mathrm{~h}$ treatment, the $\gamma$-phase can be still observed at grain boundaries as shown in Fig. 4(b). For convenience, we designate the two step solution treatment as T4-I and the corresponding T6 treatment as T6-I, and the other is T4 and T6 respectively.

After solution heat treatment, aging processes were carried out at $180^{\circ} \mathrm{C}$ for $20 \mathrm{~h}$. Figure 4 shows the microstructures of the alloy after aging treatment. In T6 treated alloy, in addition to some unsolved $\gamma$-phase, some fine precipitates are dispersed at grain boundaries and developed into grain interior (Fig. 5(b)). In T6-I alloy, as all Mg-Al-Zn phase were dissolved, the concentration of the saturated solid solution is higher. As a result, more precipitates can be formed and uniformly dispersed throughout the matrix (Fig. 5(a)). The XRD analysis results as shown in Fig. 6 indicate that heat treatment does not change secondary phases existing in the alloy.

\subsection{Mechanical properties}

The tensile stress-strain curves are shown in Fig. 7. It can be seen that the yield strength increase and the ductility decrease after both conditions of heat treatment, but the ultimate tensile strength can be improved after the T6-I treatment, while decreased in traditional T6 condition. With further examining the results, it can be inferred that the precipitates morphology has greatly influenced the tensile properties of the alloy. The continuous phase presents in the as-cast alloy may pave the way for an easy grain boundary failure during deformation. In the T6 treated sample, most of the secondary phases are dissolved into matrix and then decompose from saturated solid solution during aging as granular or fine precipitate dispersed in the matrix, thus the 
yield strength of the alloy increases after T6 treatment. However, the existence of unsolved $\gamma$-phase distributing along grain boundaries restricts its ultimate strength and ductility. On the other hand, in the alloy after T6-I treatment, all grain boundary continuous phases are first dissolved by solid solution treatment and then precipitate from the saturated $\mathrm{Mg}$ solid solution during aging process. The granular or fine precipitates which are dispersed uniformly throughout the grains can effectively hinder dislocation movement thus leading to higher tensile strength.

\section{Conclusions}

(1) The microstructure of AZ64 is mainly composed of $\alpha$ $\mathrm{Mg}, \gamma$-phase and $\phi$-phase.

(2) Thermal analysis results reveal that the solidification sequences of AZ64 under non-equilibrium condition is: (1) nucleation of primary $\alpha-\mathrm{Mg}$; (2) non-equilibrium binary eutectic of $\mathrm{Mg}$ and $\gamma$-phase; (3) ternary eutectic of $\mathrm{Mg}+\gamma$-phase $+\phi$-phase.

(3) A two-step solution teat treatment method was developed for optimizing the mechanical properties of AZ64 alloy.
(4) Using the optimized heat treatment process higher mechanical properties are obtained compared to traditional heat treated alloy and base alloy.

\section{Acknowledgement}

Thanks should be given to National Basic Research Program of China (973 Program) through project No. 2007CB613704 and Natural Sciences Foundation of China through project No. 50574086, respectively, for their financial supports.

\section{REFERENCES}

1) A. A. Luo: Inter. Mater. Rev. 49 (2004) 13-30.

2) Y. Q. Ma, R. S. Chen and E. H. Han: Mater. Sci. Forum. 488-489 (2005) 265-268.

3) Y. Q. Ma, R. S. Chen and E. H. Han: Mater. Lett. 61 (2007) 2527-2530.

4) S. M. Liang, R. S. Chen, J. J. Blandin, M. Suery and E. H. Han: Mater. Sci. Eng. A (2007), in press, available online 19 July 2007 on http:// www.sciencedirect.com.

5) H. Liang, S. Chen and Y. Chang: Metall. Mater. Trans. A 28 (1997) 1725-1734. 